\title{
Eco-Physiological Response of Conifers \\ from High-Latitude and -Altitude Eurasian Regions \\ to Stratospheric Volcanic Eruptions
}

\author{
Olga V. Churakova (Sidorova) $)^{\mathrm{a}, \mathrm{b}, \mathrm{c} *}$, Marina V. Fonti ${ }^{\mathrm{a}, \mathrm{c}}$, \\ Alexander V. Kirdyanov a,d,e, Vladimir S. Myglan ${ }^{a}$, \\ Valentin V. Barinova, Irina V. Sviderskaya ${ }^{a}$, Oksana V. Naumova ${ }^{a}$, \\ Dmitriy V. Ovchinnikov ${ }^{d}$, Alexander V. Shashkin ${ }^{d}$, Matthias Saurer ${ }^{c, f}$, \\ Sébastien Guillet ${ }^{\mathrm{b}}$, Christophe Corona ${ }^{\mathrm{g}}$, Patrick Fontic, \\ Irina P. Panyushkina ${ }^{\text {h }}$, Ulf Büntgen ${ }^{\mathrm{c}, \mathrm{e}}$, Malcolm K. Hughes ${ }^{\mathrm{h}}$, \\ Rolf T.W. Siegwolf ${ }^{\mathrm{c}, \mathrm{f}}$, Markus Stoffel ${ }^{\mathrm{b}}$ and Eugene A. Vaganov ${ }^{\mathrm{a}, \mathrm{d}}$ \\ ${ }^{a}$ Siberian Federal University \\ Krasnoyarsk, Russian Federation \\ ${ }^{b}$ University of Geneva \\ Geneva, Switzerland \\ 'Swiss Federal Research Institute for Forest, \\ Snow and Landscape WSL \\ Birmensdorf, Switzerland \\ ${ }^{d}$ Sukachev Institute of Forest SB RAS \\ FRC "Krasnoyarsk Science Center SB RAS" \\ Krasnoyarsk, Russian Federation \\ ${ }^{e}$ University of Cambridge \\ Cambridge, England \\ ${ }^{f}$ Paul Scherrer Institute \\ Villigen-PSI, Switzerland \\ ${ }^{\circ}$ Université Blaise Pascal \\ Clermont-Ferrand, France \\ ${ }^{h}$ University of Arizona \\ Tucson, USA
}


Abstract. Stratospheric volcanic eruptions have had significant impacts on the radiation budget, atmospheric and surface temperatures, precipitation and regional weather patterns, resulting in global climatic changes. The changes associated with such eruptions most commonly result in cooling during several years after events. This study aimed to reveal eco-physiological response of larch trees from northeastern Yakutia (YAK), eastern Taimyr (TAY) and Altai (ALT) regions to climatic anomalies after major volcanic eruptions CE 535, 540, 1257, 1641, 1815 and 1991 using new multiple tree-ring parameters: tree-ring width (TRW), maximum latewood density (MXD), cell wall thicknesses (CWT), $\delta^{13} \mathrm{C}$ and $\delta^{18} \mathrm{O}$ in tree-ring cellulose. This investigation showed that TRW, CWT, MXD and $\delta^{18} \mathrm{O}$ chronologies recorded temperature signal, while information about precipitation and vapor pressure deficit was captured by $\delta^{13} \mathrm{C}$ chronologies. Sunshine duration was well recorded in $\delta^{18} \mathrm{O}$ from YAK and ALT. Tree-ring parameters recorded cold, wet and cloudy summer anomalies during the $6^{\text {th }}$ and $13^{\text {th }}$ centuries. However, significant summer anomalies after Tambora (1815) and Pinatubo (1991) eruptions were not captured by any tree-ring parameters.

Keywords: $\delta^{13} \mathrm{C}$ and $\delta^{18} \mathrm{O}$ in tree-ring cellulose, tree-ring width, maximum latewood density, cell wall thickness, air temperature, precipitation, sunshine duration, vapor pressure deficit

Citation: Churakova (Sidorova) O.V., Fonti M.V., Kirdyanov A.V., Myglan V.S., Barinov V.V., Sviderskaya I.V., Naumova O.V., Ovchinnikov D.V., Shashkin A., Saurer M., Guillet S., Corona C., Fonti P., Panyushkina I., Büntgen U., Hughes M.K., Siegwolf R.T.W., Stoffel M., Vaganov E.A. Eco-physiological response of conifers from high-latitude and -altitude Eurasian regions to stratospheric volcanic eruptions. J. Sib. Fed. Univ. Biol., 2020, 13(1), 5-24. DOI: 10.17516/1997-1389-0313 


\section{Экофизиологический отклик хвойных}

\section{из высокоширотных и высокогорных районов Евразии на стратосферные извержения вулканов}

О.В. Чуракова (Сидорова) ${ }^{\mathrm{a}, \tilde{\sigma, \mathrm{B}}}$, М.В. Фонти ${ }^{\mathrm{a}, \mathrm{B}}$, А.В. Кирдянов ${ }^{\mathrm{a}, \mathrm{r}, \mathrm{\mu}}$, В.С. Мыглан ${ }^{a}$, В.В. Баринов ${ }^{\text {a }}$, И.В. Свидерская ${ }^{a}$, О.В. Наумова ${ }^{a}$, Д.В. Овчинников ${ }^{\mathrm{r}}$, А.В. Шашкин ${ }^{\mathrm{r}}$ М. Саурер ${ }^{\mathrm{s}, \mathrm{e}}$, С. Гуле ${ }^{\sigma}$, К. Корона ${ }^{*}$, П. Фонти ${ }^{\text {в }, ~ И . П . ~ П а н ю ш к и н а ~}{ }^{3}$ У. Бюнтген ${ }^{\text {в, }}$, М.К. Хьюс ${ }^{3}$, Р. Т.В. Сиегвольф ${ }^{\mathrm{B}, \mathrm{e}}$, М. Стоффель ${ }^{\sigma}$, Е.А. Ваганов ${ }^{\mathrm{a}, \mathrm{r}}$ ${ }^{a}$ Сибирский федеральный университет

Российская Федераиия, Красноярск

${ }^{6}$ Университет Женевь Швейцария, Женева ${ }^{6}$ Швейиарский федеральный институт леса, снега и ландшафта Швейцария, Бирменсдорф 'Институт леса им. В.Н. Сукачева СО РАН ФИЦ «Красноярский научный иентр СО РАН»

Российская Федерация, Красноярск ${ }^{\partial}$ Кембриджский университет Англия, Кембридж ${ }^{\text {e} И н с т и т у т ~ П а у л я ~ Ш е р р е р а ~}$ Швейчария, Филлиген - PSI

жУниверситет Блеза Паскаля Франциия, Клемон-Ферранд

${ }^{3}$ Университет Аризонь США, Тусон

Аннотация. Стратосферные вулканические извержения вызывают значительные изменения радиационного баланса, атмосферных температур и региональных погодных условий, что в свою очередь оказывает влияние на состояние глобальной циркуляции атмосферы. Данные изменения, ассоциированные с такими извержениями, в большинстве случаев приводят к глобальному похолоданию в течение нескольких лет после событий. Целью исследования стало выявление экофизиологического отклика деревьев лиственницы на северо-востоке Якутии (YAK), востоке Таймыра (TAY) и Алтае (ALT) на климатические аномалии, вызванные мощными вулканическими извержениями 535, 540, 1257, 1640, 1815 и 1991 годов н.э. с использованием разных параметров годичных колец деревьев: ширина годичного кольца (TRW), максимальная плотность поздней древесины (MXD), толщина клеточной стенки (CWT), соотношение стабильных изотопов углерода и кислорода $\left({ }^{13} \mathrm{C} /{ }^{12} \mathrm{C}\right.$ и $\left.{ }^{18} \mathrm{O} /{ }^{16} \mathrm{O}\right)$ в целлюлозе годичных колец. Данное исследование показало, что хронологии по TRW, CWT, MXD и $\delta^{18} \mathrm{O}$-хронологии содержат температурный сигнал, в то время как информация об осадках и дефиците упругости водяного пара зафиксирована в хронологиях $\delta^{13} \mathrm{C}$. Информация о продолжительности солнечного сияния хорошо отразилась в хронологии $\delta^{18} \mathrm{O}$ регионов YАK 
и ALT. Параметры годичных колец деревьев зафиксировали информацию о холодных, влажных и облачных летних погодных аномалиях в течение VI и XIII вв. Однако аномалий погодных условий в Сибири в летний период после извержений Тамбора (1815) и Пинатубо (1991) исходя из параметров годичных колец деревьев выявлено не было.

Ключевые слова: $\delta^{13} \mathrm{C}$ и $\delta^{18} \mathrm{O}$ в целлюлозе, ширина годичного кольца, максимальная плотность поздней древесины, толщина клеточной стенки, температура воздуха, осадки, продолжительность солнечного сияния, дефицит упругости водяного пара.

Цитирование: Чуракова (Сидорова), О.В. Экофизиологический отклик хвойных из высокоширотных и высокогорных районов Евразии на стратосферные извержения вулканов / О.В. Чуракова (Сидорова), М.В. Фонти, А.В. Кирдянов, В.С. Мыглан, В.В. Баринов, И.В. Свидерская, О.В. Наумова, Д.В. Овчинников, А.В. Шашкин, М. Саурер, С. Гуле, К. Корона, П. Фонти, И.П. Панюшкина, У. Бюнтген, М.К. Хьюс, Р. Т.В. Сиегвольф, М. Стоффель, Е.А. Ваганов // Журн. Сиб. федер. ун-та. Биология, 2020. 13(1). С. 5-24. DOI: 10.17516/1997-1389-0313

\section{Введение}

Глобальные климатические изменения, связанные с вулканическими извержениями, чаще всего приводят к понижению температуры приземного слоя атмосферы на 0,6-1,3 ${ }^{\circ} \mathrm{C}$ в течение нескольких лет после события (Robock, 2000). В результате мощных стратосферных вулканических извержений (VEI $\geq 4)$ продукты извержения (в частности, $\mathrm{SO}_{4}{ }^{2-}$ ) попадают в стратосферу, где могут оставаться несколько лет. Длительное нахождение в стратосфере пылевой завесы приводит к снижению солнечной радиации, “блокингу” глобальной атмосферной циркуляции (Robock, 2000). В то же время по данным климатических моделей в Европе и Сибири было выявлено уменьшение количества атмосферных осадков после мощных стратосферных извержений (Robock, Liu, 1994; Iles, Hegerl, 2014; Wegmann et al., 2014; Gillett et al., 2004). Более того, стратосферные извержения вулканов могут также приводить к зимнему потеплению на северных континентах (Kelly et al., 1996; Robock, Мао, 1992) вследствие положительной фазы арктической (АО) и Северо-Атлантической (NAO) циркуляций (Groisman, 1992; Robock, Mao, 1992).
Архивные исторические документы могут предоставить ценную информацию об извержениях вулканов и последующих климатических изменениях (Stothers, 2000). Кроме того, анализ содержания частиц пыли и кислоты в слоях ледниковых кернов дает возможность для точной датировки вулканических извержений и описания их воздействия на климат (Zielinski et al., 1994). Точные календарные датировки годичных колец деревьев обеспечивают прочную основу для их использования в качестве палеоклиматических архивов, содержащих информацию о мощных вулканических извержениях (LaMarche, Hirschboeck, 1984; Lough, Fritts, 1987; Briffa et al., 1998; Hughes et al., 1999; D’Arrigo et al., 2001; Krakauer, Randerson, 2003; Sidorova et al., 2005; Salzer, Hughes, 2007; Churakova (Sidorova) et al., 2014, 2016, 2019; Barinov et al., 2018).

Уникальным архивом данных о ежегодных изменениях климата, в том числе климатических аномалиях, является структура годичных колец деревьев (Schweingruber, 1996). Изменения величины максимальной плотности годичных колец, а также их анатомических параметров, например толщины клеточной стенки, содержат информацию об 
изменениях климата, вызванных мощными стратосферными вулканическими извержениями. Интерпретация этой информации основана на том факте, что ширина и плотность годичных колец деревьев, произрастающих вблизи полярной или верхней границы леса, содержат значимую информацию об изменчивости летней температуры воздуха, что показано в многочисленных исследованиях (Fritts, 1976; Schweingruber, 1996; Hughes et al., 1999; Vaganov et al., 2006). Заметно меньшее внимание уделялось тому, как элементный и изотопный состав древесины годичных колец изменялся в те периоды, когда они могли подвергаться влиянию удаленных вулканических извержений. Тем не менее в нескольких исследованиях установлено, что по элементному составу годичных колец возможно выявить отклик деревьев как на локальные, так и пространственно удаленные извержения (Pearson et al., 2009). Стоит также отметить, что в некоторых исследованиях, использующих изотопные сигналы в годичных кольцах деревьев средних широт (Battipaglia et al., 2007) и субарктических районов Канады (Gennaretti et al., 2017), также было выявлено влияние извержений вулканов.

Исследование отклика деревьев лиственницы, произрастающих в высокоширотных и высокогорных районах Евразии, на мощные стратосферные вулканические извержения с привлечением многопараметрического подхода, использующего данные по ширине годичных колец деревьев (TRW), максимальной плотности поздней древесины (MXD), толщине клеточной стенки трахеид (CWT), соотношению стабильных изотопов углерода $\left(\delta^{13} \mathrm{C}\right)$ и кислорода $\left(\delta^{18} \mathrm{O}\right)$ в целлюлозе годичных колец является уникальным как для российского, так и для мирового уровня (Churakova (Sidorova) et al., 2014; 2019). Данный подход c использованием нескольких параметров древесных колец позволит расширить наши знания и понимание об изменении климата и условий окружающей среды после мощных вулканических извержений. Сравнение климатического сигнала между параметрами годичного кольца и изотопной композиции углерода и кислорода в целлюлозе годичных колец деревьев лиственниц, произрастающих в высокоширотных и высокогорных районах Евразии, даст возможность выявить вариацию во времени, продолжительности вулканических событий, их интенсивности, а также однородности либо неоднородности сигнала, зафиксированного деревьями для этих районов исследования.

\section{Материалы и методы исследования}

Основываясь на ранее построенных длительных древесно-кольцевых хронологиях для северо-востока Якутии (YAK) (Hughes et al., 1999; Сидорова, Наурзбаев, 2002), востока Таймыра (TAY) (Naurzbaev et al., 2002) и Алтая (ALT) (Myglan et al., 2008), были выбраны периоды, характеризующиеся проявлением вулканической активности с известными и неизвестными стратосферными вулканическими извержениями: 516-560, 1242-1286, 1625-1675, 1790-1835 и 1950-2000 гг. н.э. (табл. 1).

Были измерены и проанализированы максимальная плотность поздней древесины (MXD), толщина клеточной стенки трахеид (CWT), соотношение стабильных изотопов углерода $\left({ }^{13} \mathrm{C} /{ }^{12} \mathrm{C}\right)$ и кислорода $\left({ }^{18} \mathrm{O} /{ }^{16} \mathrm{O}\right)$ в целлюлозе годичных колец деревьев. Репликация образцов для каждого из параметров годичного кольца является стандартной и качественно подтверждена в ранее опубликованных работах (Loader et al., 1997; Panyushkina et al., 2003; Sidorova et al., 2008, 2010).

Данные MXD для периода с 1407 по 2007 г. н.э. по ALT были взяты из публикации Шнайдер и соавторов (Schneider et al., 2015), а 
Таблица 1. Стратосферные вулканические извержения последних 1500 лет, исследованные в данной работе

Table 1. Summary of stratospheric volcanic eruptions over the past 1500 years investigated in this study

\begin{tabular}{|c|c|c|c|c|c|}
\hline $\begin{array}{c}\text { Год/месяц/день } \\
\text { извержения }\end{array}$ & $\begin{array}{c}\text { Название } \\
\text { вулкана }\end{array}$ & $\begin{array}{c}\text { Индекс } \\
\text { вулканической } \\
\text { активности } \\
\text { (VEI) }\end{array}$ & $\begin{array}{c}\text { Оптическая } \\
\text { глубина, } \tau\end{array}$ & Координаты & Литература \\
\hline $535 / ? / ?$ & Неизвестно & $6+?$ & $?$ & Неизвестно & Stothers, 1984a, 1999 \\
\hline $540 / ? / ?$ & Неизвестно & $?$ & $?$ & Неизвестно & $\begin{array}{l}\text { Sigl et al., 2013, 2015; } \\
\text { Toohey, Sigl, } 2017\end{array}$ \\
\hline $1257 / 09 / ?$ & Самалас & 7 & 0,39 & Индонезия & $\begin{array}{l}\text { Stothers, 2000; Sigl et } \\
\text { al., } 2015\end{array}$ \\
\hline $1640 / 12 / ?$ & Паркер & 5 & 0,18 & $\begin{array}{l}\text { Филлипины, } \\
6^{\circ} \text { с. ш., } 124^{\circ} \text { в. д. }\end{array}$ & Zielinski et al., 1994 \\
\hline $1815 / 04 / 10$ & Тамбора & 7 & 0,20 & $\begin{array}{l}\text { Индонезия, } \\
8^{\circ} \text { ю. ш., } 118^{\circ} \text { в. д. }\end{array}$ & $\begin{array}{l}\text { Stothers, 1984b; } \\
\text { Zielinski et al., } 1994\end{array}$ \\
\hline 1991/06/12 & Пинатубо & 6 & 0,12 & $\begin{array}{l}\text { Филлипины, } \\
15^{\circ} \text { с. ш., } 120^{\circ} \text { в. д. }\end{array}$ & $\begin{array}{l}\text { Zielinski et al., 1994; } \\
\text { Sigl et al., } 2015\end{array}$ \\
\hline
\end{tabular}

для ҮАК с 1790 по 2004 г. - из работы Сидоровой и соавторов (Sidorova et al., 2010). Для других периодов были проведены измерения плотности древесины для как минимум шести образцов (Schweingruber, 1996). Для периода с 520 по 560 г. н.э. было использовано только четыре образца, так как в остальных образцах кольца 536 и 537 г. н.э. отсутствовали. Измерения максимальной плотности годичных колец проводили в Институте леса им. В.Н. Сукачева СО РАН и Швейцарском Институте снега, леса и ландшафта по широко апробированной методике, подробно описаной Швайнгрубером в 1996 г. (Schweingruber, 1996).

Данные по толщине клеточной стенки трахеид (CWT) для ALT в периоды с 1790 по 1835 и с 1950 по 2000 г. н.э. были взяты из ранее опубликованных исследований (Sidorova et al., 2012; Fonti et al., 2013) и для YAK в период с 1600 по 1980 г. н.э. - данные, опубликованные Панюшкиной с соавторами (Panyushkina et al., 2003). Получение клеточных хронологий $(\mathrm{n}=4)$ для других периодов и их анализ были проведены в Институте леса им. В.Н. Сукачева СО РАН.
Анализ изотопного соотношения углерода $\left({ }^{13} \mathrm{C} /{ }^{12} \mathrm{C}\right)$ и кислорода $\left({ }^{18} \mathrm{O} /{ }^{16} \mathrm{O}\right)$ или величины $\left(\delta^{13} \mathrm{C}\right)$ и $\left(\delta^{18} \mathrm{O}\right)$ в целлюлозе годичных колец деревьев был осуществлен в Институте Пауля Шеррера (PSI, Швейцария) для всех периодов исследования (Sidorova et al., 2008, 2010, 2012, 2013; Churakova (Sidorova) et al., 2014). Для каждого периода исследования было использовано четыре древесных образца (6-8 фрагментов древесного диска).

При анализе реакции древесных колец на изменения условий роста после вулканических извержений был использован метод наложенных эпох ( \pm 15 лет до и после извержения) (Panofsky, Brier, 1958). Он был применен для всех параметров годичного кольца и для каждого вулканического извержения (535, 1257, 1640, 1815, 1991 гг.) для северо-востока Якутии (YAK), востока Таймыра (ТАY) и Алтая (ALT). Все вычисления выполнены в программе R Core Team 2016 (R Core Team, 2016).

Для выявления климатических факторов, определяющих изменчивость того или иного древесно-кольцевого параметра, были рассчитаны коэффициенты корреляции с клима- 
Таблица 2. Характеристики исследуемых участков и местоположения метеорологических станций

Table 2. Statistics for locations of study sites and weather stations

\begin{tabular}{|c|c|c|c|c|c|c|c|c|c|c|}
\hline \multirow[b]{2}{*}{ 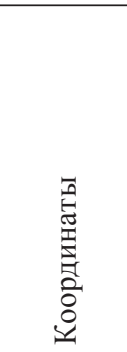 } & \multirow[b]{2}{*}{ 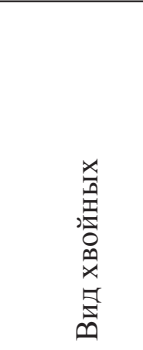 } & \multirow[b]{2}{*}{ 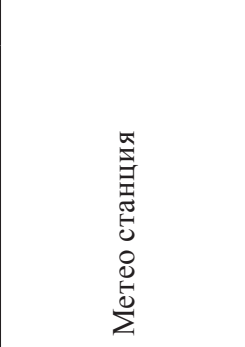 } & \multicolumn{4}{|c|}{ Период наблюдений } & \multirow[b]{2}{*}{ 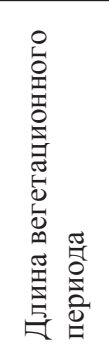 } & \multirow[b]{2}{*}{ 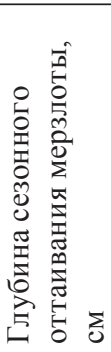 } & \multirow[b]{2}{*}{ 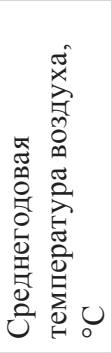 } & \multirow[b]{2}{*}{ 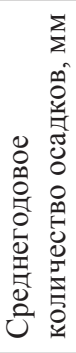 } \\
\hline & & & 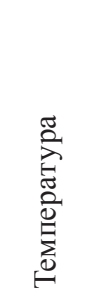 & 旡 & 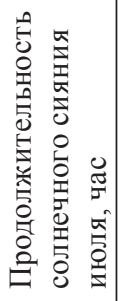 & 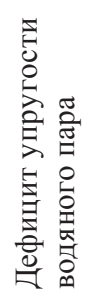 & & & & \\
\hline $\begin{array}{l}\text { YAK } \\
69^{\circ} \text { с.ш. } \\
148^{\circ} \text { в.Д. }\end{array}$ & $\begin{array}{l}\text { Larix } \\
\text { cajanderi } \\
\text { Mayr. }\end{array}$ & $\begin{array}{l}\text { Чокурдах } \\
62^{\circ} \text { с.ш. } 147^{\circ} \text { в.д. } \\
61 \text { м над у.м. }\end{array}$ & $\begin{array}{l}1950- \\
2000\end{array}$ & $\begin{array}{l}1966- \\
2000\end{array}$ & $\begin{array}{l}1961- \\
2000\end{array}$ & $\begin{array}{l}1950- \\
2000\end{array}$ & $50-70 *$ & $20-50 *$ & $-14,7$ & 205 \\
\hline $\begin{array}{l}\text { TAY } \\
70^{\circ} \text { с.ш. } \\
103^{\circ} \text { в.д. }\end{array}$ & $\begin{array}{l}\text { Larix } \\
\text { gmelinii } \\
\text { Rupr. }\end{array}$ & $\begin{array}{l}\text { Хатанга } \\
71^{\circ} \text { с.ш. } 102^{\circ} \text { в.д. } \\
33 \text { м над у.м. }\end{array}$ & $\begin{array}{l}1950- \\
2000\end{array}$ & $\begin{array}{l}1966- \\
2000\end{array}$ & $\begin{array}{l}1961- \\
2000\end{array}$ & $\begin{array}{l}1950- \\
2000\end{array}$ & $90 * *$ & $\begin{array}{l}40- \\
60 * *\end{array}$ & $-13,2$ & 269 \\
\hline $\begin{array}{l}\text { ALT } \\
50^{\circ} \text { с.ш. } \\
89^{\circ} \text { в.д. }\end{array}$ & $\begin{array}{l}\text { Larix } \\
\text { sibirica } \\
\text { Ledeb. }\end{array}$ & $\begin{array}{l}\text { Мугур-Аксы } \\
50^{\circ} \text { с.ш. } 90^{\circ} \text { в.д. } \\
1850 \text { м над у.м. }\end{array}$ & $\begin{array}{l}1963- \\
2000\end{array}$ & $\begin{array}{l}1966- \\
2000\end{array}$ & н.д. & н.д. & $\begin{array}{c}90- \\
120 * * *\end{array}$ & $\begin{array}{c}80- \\
100 * * *\end{array}$ & $-2,7$ & 153 \\
\hline
\end{tabular}

Примечание: *Абаимов и др., 1997; Hughes et al., 1999; Churakova (Sidorova) et al., 2016; **Naurzbaev et al., 2002; ***Sidorova et al., 2012.

тическими данными (табл. 2), полученными с ближайших метеорологических станций. При расчетах использован метод вероятностных распределений, основанных на многократной генерации выборок методом Монте-Карло на базе имеющейся выборки.

\section{Результаты и обсуждение}

Аномалии, зафиксированные

параметрами годичных колеи деревьев

и стабильными изотопами

после вулканических извержений

В результате анализа с использованием метода наложенных эпох выявлено, что значимые изменения параметров колец наблюдались для хронологий, полученных по толщине клеточной стенки трахеид. Причем у деревьев лиственницы, росших в Якутии и на Таймыре, эти изменения происходили сразу же после извержений, а на Алтае - двумя годами позже (рис. 1). В Якутии величина соотношения изотопов кислорода $\left(\delta^{18} \mathrm{O}\right)$ в цел- люлозе годичных колец существенно уменьшалась в первый год после извержений, тогда как у деревьев на полуострове Таймыр и горном Алтае - в течение последующих двух лет. Изменения $\delta^{13} \mathrm{C}$ и $\delta^{18} \mathrm{O}$ в целлюлозе годичных колец в 536 г. н.э. происходили немедленно после извержения и не имеют аналогов за последние 1500 лет.

\section{Стратосферные извержения вулкана 535 и 541 г2. н.э.}

Исследования, нацеленные на понимание зафиксированных в годичных кольцах деревьев последствий извержений вулканов, проводимые с использованием нескольких параметров древесных колец, особенно необходимы, так как годичные кольца деревьев позволяют с точностью до года определить календарную дату, что затруднительно для других палеоклиматических косвенных источников информации (ледниковые и озерные керны или споро-пыльцевые спектры). Мно- 


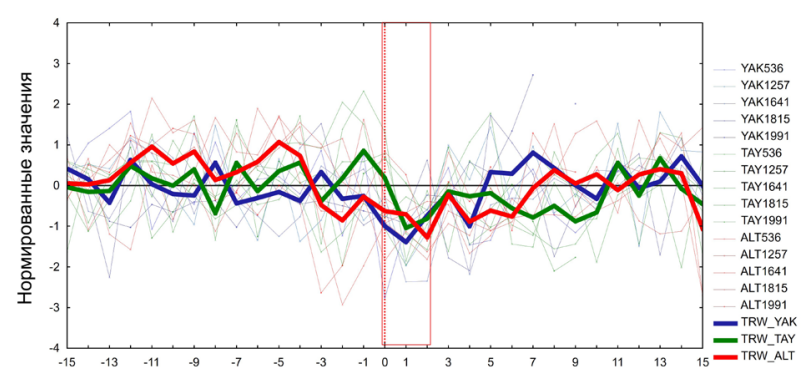

TRW
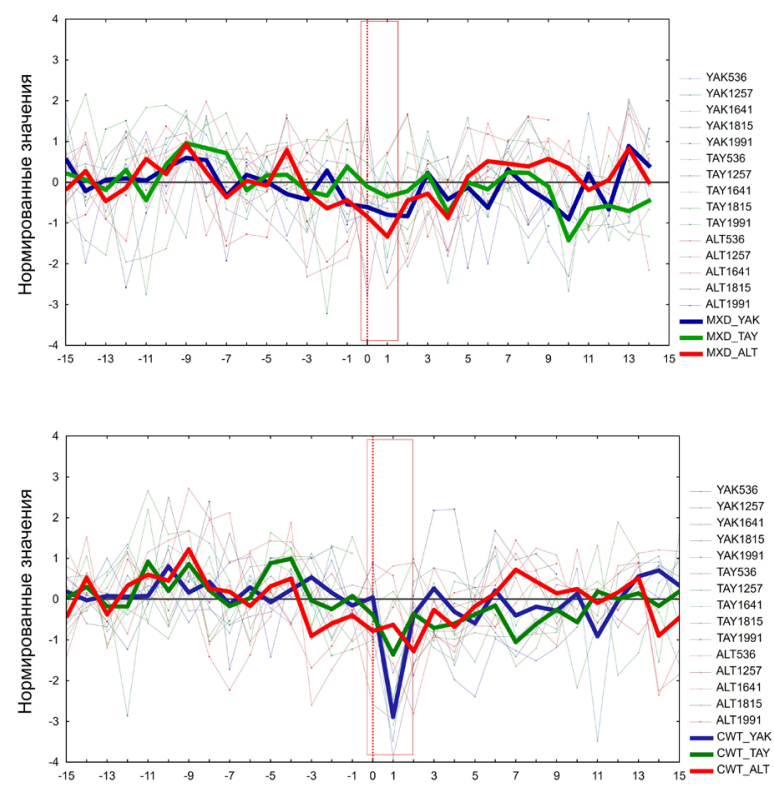

CWT
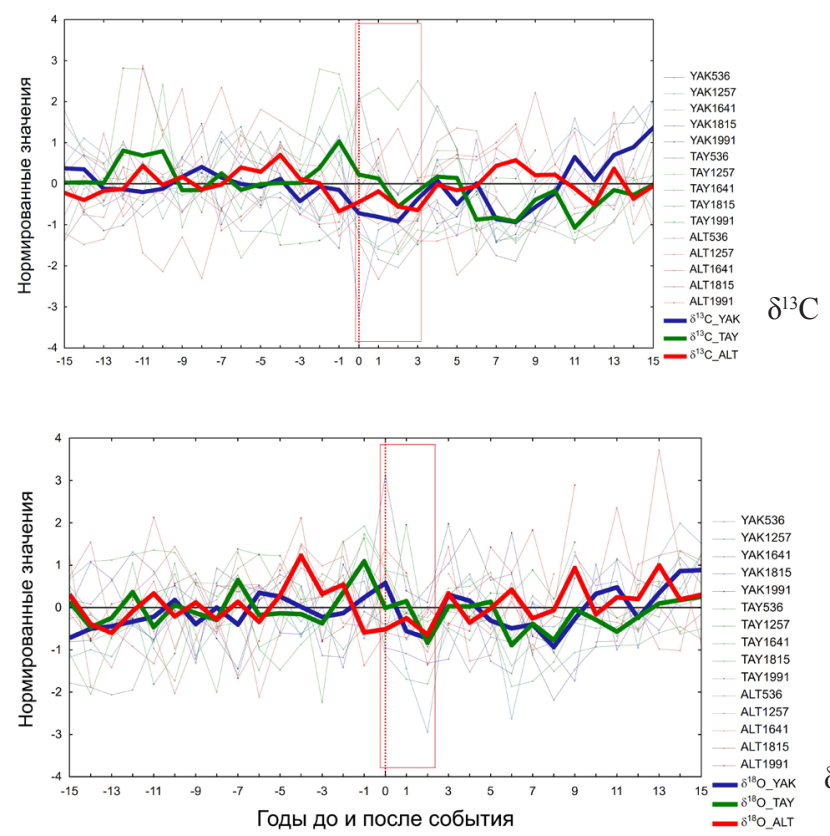

Рис. 1. Нормированные значения (z-score) для параметров годичного кольца (TRW, MXD, CWT, $\delta^{13} \mathrm{C}$ и $\left.\delta^{18} \mathrm{O}\right)$ для каждого вулканического извержения (536 г., 1257 г., 1641 г., 1815 г., 1991 г.), рассчитанные методом наложенных эпох ( \pm 15 лет до и после извержения относительно 0) для северовостока Якутии (YАK, синяя линия), востока Таймыра (TAY, зеленая линия) и Алтая (ALT, красная линия). Периоды пост-вулканических событий обозначены прямоугольниками.

Fig. 1. Z-score of tree-ring parameters for volcanic eruptions: AD 536, 1257 1641, 1815, and 1991, computed with the Superposed Epoch Analysis $( \pm 15$ years before and after the event - relative to the zero) from the northeastern Yakutia (YAK, blue line), the eastern Taimyr (TAY, green line) and the Altai (ALT, red line). The post-volcanic periods are marked by rectangles. 
гие работы посвящены исследованию пылевой завесы 536 г. н.э., появившейся вследствие неизвестного события (Baillie, 1994; Zielinski et al., 1994; Briffa et al., 1998; Stothers, 1999; D'Arrigo et al., 2001; Rigby et al., 2004). Это один из наиболее холодных периодов в Северном полушарии за последние два тысячелетия, по данным древесно-кольцевых хронологий и исторических источников (Stothers, 1999; Briffa et al., 1998; Larsen et al., 2008; Churakova (Sidorova) et al., 2014; Büntgen et al., 2016). Химический анализ ледниковых кернов Гренландии указывает на увеличение сульфатов в 535 г. н.э. (Plummer et al., 2012). Предполагается, что сухие вулканические туманы и равномерно распределенные частицы пыли в атмосфере, порожденные событиями 530-540-х гг., в частности вследствие извержений 536 и 541 гг. н.э., привели к охлаждению приземного слоя атмосферы, задерживая солнечный свет и нарушая характер атмосферной циркуляции. Исторические документы дают информацию об эпидемиологических последствиях этих сухих вулканических туманов, наблюдавшихся в Европе и на Ближнем Востоке (Stothers, 1999). Данные, полученные из исторических документов, согласуются с данными по древесным кольцам и измерениям кислотности полярного льда (Stothers, 1999; Larsen et al., 2008; Guiliet et al., 2017). Стоверс (Stothers, 1999) приписал эти события «неизвестному» вулкану, извержение которого, как считается, произошло в марте 536 г. где-то в северных широтах. В европейских хронологиях ширины годичных колец деревьев отмечается замедление роста деревьев в течение по меньшей мере 10 лет после события 536 г. (Stothers, 1999; Baillie, 1994; Büntgen et al., 2016). Альтернативная гипотеза предполагает, что вторжение космического тела (астероида или кометы) в атмосферу могло стать причиной климатических изменений в это время (Rigby et al., 2004). Полученная ранее хронология по содержанию сульфатов в ледниковом керне Гренландии имеет пробел в этот период и показывает увеличение концентрации только в предполагаемом 529 г. (Zielinski et al., 1994). Однако недавние исследования показали (Gao et al., 2008; Larsen et al., 2008; Sigl et al., 2015) большую концентрацию вулканической серной кислоты в ледниковых кернах Гренландии и Антарктики для события 536 г., что поддерживает изначальную гипотезу извержения вулканов. Современные исследования кислотности в ледниковых кернах из Гренландии и Антарктики указывают, что за несколько лет до 536 г. произошло два или, возможно, даже три вулканических извержения (Plummer et al., 2012; Sigl et al., 2015). В частности, Сигл с соавторами (Sigl et al., 2013), анализируя ледниковые керны, выявили несколько событий в Антарктиде/Гренландии $(528,7 / 529,8 ; 531,2 / 532,5 ; 530,2 / 531,5$ и $534,6 / 535,0)$, что свидетельствует о глобальном характере влияния на климат этой серии извержений. В обоих рядах отмечается более высокое осаждение вулканического сульфата в Гренландии по сравнению с Антарктидой. Обозначим их «извержениями, произошедшими в 532 и 536 гг.», сравнивая с событиями, зафиксированными параметрами годичных колец, с целью календарного датирования вулканического извержения. Сигл и соавторы (Sigl et al., 2013) также сообщают о третьем событии с меньшим осаждением вулканического сульфата, признаки которого присутствуют только в ледниковом керне из Гренландии, начиная с 539,5 и заканчивая 541 г. н.э. Мы будем называть это «извержением 541 г.», также делая предварительную ссылку на данные, полученные для высокоширотных районов Евразии (Churakova (Sidorova) et al., 2014). Очевидные улучшения в датировке ледниковых кернов (Larsen et al., 2008; Plummer et al., 
2012; Sigl et al., 2013, 2015) и точности хронологии по осаждению вулканической серы и, следовательно, вулканических лет, позволили произвести пересмотр роли так называемого глобального катастрофического события 536 г. н.э. Третье извержение, по-видимому, закончилось пять лет спустя, в 541 г. н.э.

Предположим, что кластер вулканических событий, центрированный в 536 г. н.э., привел к понижению радиального роста деревьев из-за совместного влияния таких факторов, как уменьшение солнечного излучения, снижение температуры и снижение упругости водяного пара для высокоширотных (Якутия, Таймыр) и высокогорных (Алтай) районов Евразии.

С использованием древесно-кольцевых хронологий (TRW), полученных для YAK, TAY и ALT, был выбран период с 520 по 560 г. и проанализирован для других параметров: максимальной плотности поздней древесины, толщины клеточной стенки трахеид и стабильных изотопов углерода и кислорода (рис. 1). Во время процедуры перекрестного датирования было обнаружено, что в большинстве образцов из ҮАК и ТАY отсутствовало кольцо 536 г. Четыре древесных образца из ҮАК, которые содержали узкое кольцо 536 г., были использованы в анализе для построения хронологий по TRW и толщине клеточной стенки, а также полу- чения данных по соотношению стабильных изотопов углерода и кислорода. Для YАK и TAY наблюдали отклонения (-2б) относительно среднего значения прироста деревьев (TRW) для 536 и 541 гг. н.э. Хронология TRW для ALT имеет относительно широкие кольца (до 0,90 мм) в начале периода. После 532 г. TRW для ALT резко снизилась до $\sim 0,40$ мм и снова после 536 г. до 0,16 мм с наименьшим значением в 539 г. (-1,9б). TRW хронологии для ALT показывают выраженное снижение радиального роста в течение 24 лет по сравнению с TRW для TAY (17 лет) и YAK (11 лет) (рис. 1).

Фотографии образцов с поврежденными клеточными структурами в кольце 536 г. представлены на рис. 2. К сожалению, оставшиеся образцы сегментов деревьев с полуострова Таймыр, которые не использовали для анализа стабильных изотопов, были повреждены во время транспортировки. Таким образом, получить четкое изображение кольца 536 г. было невозможно. В результате данные о нарушениях структуры в кольце 536 г. для деревьев с участка ТАY отсутствуют. В образцах из YAK и ALT хорошо видны очень узкие кольца, состоящие из одной-четырех клеток в радиальном файле, и характерные нарушения в клеточной структуре, так называемые морозобойные кольца, связанные с вулканическим извержением 535 г. н.э. (рис. 2). Ана-
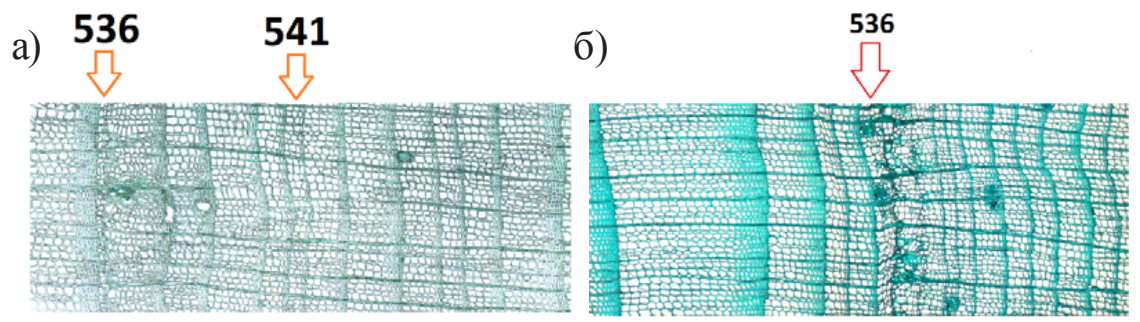

Рис. 2. Фотографии анатомических срезов древесины для 536 и 541 гг. н.э. для северо-востока Якутии (YAK) (а) и Алтая (ALT) (б)

Fig. 2. Anatomical micro sections for 536 and 541 AD from the northeastern Yakutia (YAK) (a) and Altai (ALT) (б) 
лиз изображений анатомической структуры годичного кольца показал, что деревья значимо реагируют на экстремально холодные климатические условия, образуя всего лишь две клетки в вегетационный период, в случае YAK (рис. 2a), или образуя морозобойные кольца как в образцах лиственницы сибирской ALT (рис. 2б).

Хронологии CWT были построены на основе анализа четырех образцов деревьев из каждого района исследования. У образцов, отобранных на участке YAK, CWT показывает снижение (до -2,1 б) в 536 и 541 гг., в то время как среднеквадратическое отклонение для CWT у образцов из района ALT составило $-2,9$ б. Хронология CWT не выявила увеличения толщины клеточных стенок до 541 г. На участке ALT зарегистрированы самые низкие средние, минимальные и максимальные значения толщины клеточных стенок за период 520-560 гг. н.э. (и, в частности, для 536 г. н.э.).

Значения $\delta^{13} \mathrm{C}$ в целлюлозе участков YАК и ТАY демонстрируют значимое снижение в 536 г. (-3.3 и -1.7 б соответственно). Значения $\delta^{13} \mathrm{C}$ для участка YAK показывают дальнейшее снижение и в 537 г. н.э. с небольшим провалом в 541 г. Значения $\delta^{13} \mathrm{C}$ для участка TAY оставались на низком уровне более десяти лет с минимумом в 538 г. н.э. Хронологии $\delta^{13} \mathrm{C}$, полученные для всех трех участков ҮAK, ТАY и ALT, установили различия в средних значениях до 2,6 \%. Аномально низкие значения соотношения изотопов кислорода $\delta^{18} \mathrm{O}$ для 536 г. н.э. регистрировались на высокогорном Алтае (ALT) с разностью 8 \% и стандартным отклонением $-4,8 \sigma$ относительно среднего значения для периода с 516-560 гг. н.э. (рис. 1). Низкие значения были обнаружены и для других районов исследования, включая участок TAY $(-1,9 \sigma)$ и YАK $(-1,7 \sigma)$.

Bce параметры древесного кольца для участков YAK, TAY и ALT достоверно кор- релируют друг с другом ( $\mathrm{r}=0,7-0,9 ; \mathrm{p}<0,01)$. Большинство из них продемонстрировали значительную сопряженность между участками, удаленными на расстоянии от 1400 до 3500 км друг от друга, что свидетельствует о глобальном характере события, проявившемся на территории обширного региона Сибири в 536 г. н.э.

Стратосферное извержение вулкана Самалас в 1257 г. н.э.

Извержение вулкана Самалас произошло в Индонезии в 1257 г. (Stothers, 2000; Lavigne et al., 2013; Guillet et al., 2017) и относится к числу крупнейших вулканических извержений в течение позднего голоцена с осаждением серы в ледниковых кернах в концентрациях, в два раза превышающих значения, зарегистрированные при извержении вулкана Тамборы в 1815 г. (Sigl et al., 2015). Анализ стратиграфии и отложений в ледниковых кернах Гренландии подтверждает высокую активность извержения вулкана Самалас (индекс вулканической активности VEI = 7) с выбросом магмы $\geq 40$ км$^{3}$ (Lavigne et al., 2013). Более того, климатический отклик на событие Самалас активно обсуждается для включения в климатические модели поколения GCM-CMIP6 (Stoffel et al., 2015). По данным обобщенных древесно-кольцевых хронологий для Северного полушария было выявлено, что 1258 и 1259 гг. н.э. были самыми холодными годами прошлого тысячелетия (Sidorova et al., 2005; Stoffel et al., 2015). Coобщается, что извержение вулкана Самалас обострило социально-экономический кризис в Японии и Англии (Guillet et al., 2017). Однако похолодание в Северном полушарии было пространственно-неоднородным. Предполагается, что в Северной Америке климат модулировался Эль-Ниньо и Южным осцилляциями. Однако в Сибирских хронологиях 
извержение отразилось в снижении прироста в 1258 г. для YAK и ALT и в 1259 г. для TAY (рис. 1). В хронологии Nadim, построенной на севере Западной Сибири, также наблюдается сильное снижение прироста и формирование аномалий структуры годичных колец в 1259 г. (Omurova et al., 2018).

Стратосферные извержения вулканов XVII, ХІХ и ХХ столетий н.э.

Исторические и природные климатические архивы зарегистрировали в 1640 г. мощное извержение вулкана Паркер (табл. 1). В Сибирских хронологиях данное событие нашло отклик на 2 года позже, в 1642 г. (рис. 1).

Извержению вулкана Тамбора в 1815 г. н.э., приведшему к так называемому году без лета, посвящено большое число исследований. По историческим данным, вулкан Тамбора стал причиной низкого урожая и эпидемий, повлекших гибель более чем 200000 человек по всему миру (Brönnimann, Krämer, 2016). Модели атмосферной циркуляции показывают уменьшение количества осадков в 1816 г. в Африке, Северной Америке, восточной, центральной и западной частях Азии. Климатические реконструкции демонстрируют холодное и дождливое лето в западной части Европы.

Клеточные хронологии деревьев из Якутии зафиксировали извержение Тамборы уже в структуре кольца 1816 г. Заметное изменение изотопного состава углерода в целлюлозе деревьев в горах Алтая отмечается на год позже, в 1817 г. н.э. (рис. 1).

Стратосферное извержение вулкана Пинатубо в 1991 г. н.э. (табл. 1) достаточно хорошо изучено и описано в литературе. В результате извержения вулкана Пинатубо на 10 \% снизилось поступление солнечной радиации, а среднегодовая глобальная температура воздуха уменьшилась на $0,5-0,6{ }^{\circ} \mathrm{C}$.
Одновременно с понижением температуры воздуха произошло нагревание стратосферы на несколько градусов выше средних значений вследствие абсорбции радиации аэрозолями. Стратосферные вулканические облака сохранялись в атмосфере в течение трех лет после извержения. Несмотря на глобальный климатический эффект, извержение Пинатубо не оказало значительного влияния на рост и структуру годичных колец деревьев из высокоширотных и высокогорных территорий Евразии.

Таким образом, экстремальные явления 536 и 541 гг. н.э. характеризуются аномальными изменениями толщины клеточной стенки (CWT) для YAK и ALT. Существенные изменения были зафиксированы для $\delta^{18} \mathrm{O}$ хронологии, построенной для ALT. 1258 г. очень экстремальный для CWT и TRW для всех районов исследования, в то время как аномалии 1259 г. зафиксированы в TRW, MXD и $\delta^{13}$ C. 1642 г. н.э. классифицировался как очень экстремальный для ҮАК и ТАY, но не для ALT. На хронологии YAK для кольца 1992 г. зафиксированы аномальные значения MXD и CWT. На хронологии ALT для кольца 1993 г. н.э. выявлены аномальные значения CWT и $\delta^{18} \mathrm{O}$ (рис. 1).

\section{Климатические функичии отклика} между метеорологическими данными и параметрами годичного кольца

\section{Температурный сигнал}

Корреляционный анализ позволил выявить значимые связи $(\mathrm{p}<0,05)$ для ALT между TRW (r =0,52), MXD (r=0,57), $\delta^{13} \mathrm{C}$ $(\mathrm{r}=0,38), \mathrm{CWT}(\mathrm{r}=0,28)$ и температурой воздуха июня. В то же время температура июля значимо отражается в изменчивости всех параметров годичного кольца всех районов исследования с диапазоном значения коэффициента корреляции от $\mathrm{r}=0,28$ до $\mathrm{r}=0,60$, за 
исключением хронологии ТАY по $\delta^{18} \mathrm{O}$. Температура августа оказывает влияние на изменчивость MXD и CWT для YAK ( $\mathrm{r}=0,34$ и $\mathrm{r}=0,40$ соответственно); $\delta^{18} \mathrm{O}(\mathrm{r}=0,48), \delta^{13} \mathrm{C}$ $(\mathrm{r}=0,33)$ и $\mathrm{CWT}(\mathrm{r}=0,28)$ для ALT. Наряду с общим для всех параметров положительным влиянием летних температур была выявлена статистически значимая связь между температурой воздуха февраля и $\delta^{18} \mathrm{O}$ целлюлозы для YAK и ALT ( $r=0,25$ и $r=0,26$ соответственно). Для хронологии ТАY по $\delta^{18} \mathrm{O}$ выявлены значимые связи с температурой воздуха весенних месяцев марта и мая $(\mathrm{r}=0,30$ и $r=0,35$ соответственно). Такие параметры годичных колец, как TRW, MXD и CWT, свидетельствуют о наличии летних температурных аномалий в течение 536, 541, 542, 1258 , 1259 гг. н.э. для всех районов исследования. После XIII в. снижение температуры после мощных стратосферных вулканических извержений не столь выражено по данным всех параметров годичных колец. Например, снижение летней температуры воздуха в 1641 г. было зафиксировано в изменчивости CWT для ALT, а в 1642 г. - для TRW хронологии из ҮAK.

Однако 1643 г. зафиксировали как экстремально холодный для ТАY, базируясь на данных по TRW и CWT; 1816 г. был холодным для YAK, по данным хронологии CWT. Холодный 1992 г. после извержения вулкана Пинатубо был зафиксирован в хронологиях MXD и CWT для YAK; 1993 г. был холодным для ALT по сравнению с 1992 г., по данным CWT и $\delta^{18} \mathrm{O}$ хронологий.

Сопоставление хронологий, полученных по различным параметрам годичных колец лиственницы из высокоширотных и высокогорных районов исследования, указывает на различные климатические сигналы, зафиксированные деревьями лиственниц после мощных стратосферных извержений. Длительный период с низкими летними температурами вызвал снижение фотосинтетической активности, что привело к формированию узких годичных колец в 536, 541 и 1258, 1259 гг. н.э. Исключительной особенностью за последние 1500 лет является формирование очень малого числа клеток в 536-538 гг. н.э. Так, в случае образцов из YАK для 537 г. было найдено всего 2 клетки, что существенно меньше среднего числа трахеид в кольце, в среднем изменяющегося в диапазоне 12-17 клеток для высокоширотных районов и до 30 клеток для высокогорного ALT.

Значительное уменьшение значений по $\delta^{18} \mathrm{O}$ в 536 г. $(-4,8 \sigma)$ относительно периода с 516 по 560 г. для ALT может быть объяснено экстремально низкими температурами в течение лета и формированием морозобойных колец (Myglan et al., 2008; Churakova (Sidorova) et al., 2014). Извержение вулкана Паркер в 1640 г. отразилось в Сибирских хронологиях на два года позже. Современное извержение вулкана Пинатубо в год извержения 1991 г. не отразилось на анализируемых хронологиях, и только на следующий 1992 г. было зафиксировано данное событие в YAK и в 1993 г. на ALT. Taкого рода аномалии с запаздыванием в один год или несколько лет могут быть объяснены разницей распределения пылевой завесы после извержения и нарушением атмосферной циркуляции воздуха, приводящих к повышенной облачности (Brönnimann, Krämer, 2016).

Зимние и весенние аномальные потепления после извержения вулкана Пинатубо (Robock, Mao, 1992) согласуются с хронологией по $\delta^{18} \mathrm{O}$ для TAY и ALT. Однако длительного влияния похолодания или аномальных изменений в клеточных стенках трахеид годичных колец, как это нашли для 536, 541 гг. н.э. (Churakova (Sidorova) et al., 2014, 2019), обнаружено не было. 


\section{Сигнал на осадки}

(дефицит влажности воздуха)

Были выявлены статистически значимые негативные связи между осадками июля и соотношением стабильных изотопов кислорода $\delta^{18} \mathrm{O}$ в целлюлозе годичных колец ( $\mathrm{r}=-0,34$; $\mathrm{p}<0,05)$ для ҮАК. Осадки июля значимо коррелируют также с хронологиями $\delta^{13} \mathrm{C}$ для ТАY $(\mathrm{r}=-0,51 ; \mathrm{p}<0,05)$ и $\operatorname{ALT}(\mathrm{r}=-0,54 ; \mathrm{p}<0,05)$. Значимые корреляции были выявлены между данными по осадкам августа и изотопным соотношением $\delta^{18} \mathrm{O}$ в целлюлозе лиственницы для ALT $(r=-0,29 ; \mathrm{p}<0,05)$. Напротив, для этого участка положительные значимые связи были обнаружены между осадками марта и TRW ( $\mathrm{r}=0,37 ; \mathrm{p}<0,05), \operatorname{MXD}(\mathrm{r}=0,32 ; \mathrm{p}<0,05)$, а также CWT $(r=0,34 ; \mathrm{p}<0,05)$.

Изменения среднемесячных значений дефицита влажности воздуха июня, июля и августа значимо влияют на $\delta^{18} \mathrm{O}$ в целлюлозе годичных колец для ALT ( $\mathrm{r}=0,67, \mathrm{r}=0,55$ и $\mathrm{r}=0,46)$ для периода с 1950 по 2000 г. Изотопные соотношения $\delta^{13} \mathrm{C}$ и $\delta^{18} \mathrm{O}$ в целлюлозе YАК значимо коррелируют с дефицитом упругости водяного пара (VPD) июля $(\mathrm{r}=0,69$ и $\mathrm{r}=0,31$ соответственно). Значительного влияния VPD на хронологии, полученные для ТАY, выявлено не было.

Наличие воды выступает важным условием для лиственницы, произрастающей в экстремально холодных климатических условиях в зоне сплошного распространения многолетней мерзлоты, которая может рассматриваться в качестве резервуара и дополнительного источника воды в засушливые периоды (Sugimoto et al., 2002; Boike et al., 2013; Saurer et al., 2016; Churakova (Sidorova) et al., 2016). Однако на северо-востоке Якутии (YAK) (Churakova (Sidorova) et al., 2016) талая мерзлотная вода не всегда может быть использована корнями произрастающих там деревьев вследствие физиологической струк- туры корневой системы (поверхностные корни) или низкой температуры воды (Churakova (Sidorova) et al., 2016).

Изменения количества осадков июля предполагают изменения в изотопном составе углерода в целлюлозе годичных колец, который содержит сигнал об изменении относительной влажности воздуха и доступности почвенной влаги. Значимые отрицательные статистические связи между осадками июля и $\delta^{13} \mathrm{C}$ в целлюлозе объясняются ухудшением условий увлажнения для современного периода по сравнению с VI или XIII в. н.э. Распространение пылевой завесы после мощных стратосферных извержений вулканов приводит к уменьшению приходящей солнечной радиации, что ведет в свою очередь к понижению температуры воздуха, снижению VPD и снижению фотосинтетической активности. Данный эффект зафиксирован в снижении $\delta^{13} \mathrm{C}$ в целлюлозе годичных колец.

Выявлено отсутствие значимых климатических аномалий после извержения вулкана Тамбора в течение 1815 и 1816 гг. в высокоширотных районах Азии, в то время как холодные и влажные условия были выявлены для ALT в течение лета 1817 г. По данным хронологий, полученных по стабильным изотопам углерода и кислорода, лето 1992 г. было влажным на ALT по сравнению с сухим 1991 г. Положительные связи между VPD и $\delta^{18} \mathrm{O}$ для YAK и ALT свидетельствуют, что увеличение температуры ведет к увеличению эвапотранспирации.

\section{Влияние облачности на изотопную} композицию кислорода $\left(\delta^{18} O\right)$ в целлюлозе годичных колец после стратосферных извержений вулканов

Значимое влияние продолжительности солнечного сияния в июле было зафиксировано в $\delta^{18} \mathrm{O}$ целлюлозы для $\mathrm{YAK}(\mathrm{r}=0,73$; 
$\mathrm{p}<0,05)$ и ALT $(\mathrm{r}=0,51 ; \mathrm{p}<0,05)$ для периода с 1961 по 2000 г. Инструментальные измерения длительности солнечного сияния для современного периода для YAK и ALT показывают значимую связь с $\delta^{18} \mathrm{O}$ в целлюлозе годичных колец. По данным изотопной композиции $\delta^{18} \mathrm{O}$ в целлюлозе, продолжительность солнечного сияния значительно уменьшилась в 536, 541, 542, 1258 и 1259 гг. для YАК и 536 г. для ALT. Однако лето 1991 г. (извержение вулкана Пинатубо) в YАК было солнечным.

Хронология по изотопной композиции $\left(\delta^{18} \mathrm{O}\right)$ для YAK и ALT отражает низкий уровень продолжительности летнего солнечного сияния в течение VI и XIII вв. и низкие значения летних температур. Лето 1991 г. было достаточно солнечным в сибирских районах исследования. В год извержения вулкана Пинатубо его влияние на продолжительность солнечного сияния в летний период не зафиксировано, но отмечается спустя 1 год для YAK и TAY, в то время как для ALT двумя годами позже.

\section{Заключение}

Многопараметрический подход, используемый в данной работе, позволил получить информацию об изменении осадков, дефицита влажности воздуха и облачности после крупных стратосферных извержений вулканов, т. е. факторах, которые невозможно было выявить, используя только ширину годичного кольца. Анализ изменчивости ширины древесных колец, максимальной плотности поздней древесины, толщины клеточной стенки трахеид, и $\delta^{13} \mathrm{C}$ и $\delta^{18} \mathrm{O}$ в целлюлозе годичных колец деревьев дал возможность выявить синхронность холодных и сухих летних аномалий с уменьшением суммарной продолжительности солнечного сияния в течение 1258 и 1259 гг. н.э. для высокоширотных и высокогорных районов Сибири. Однако, после стратосферных извержений вулканов 535 и 540 гг. н.э. отмечалось повышение влажности в высокоширотных районах. Стратосферные вулканические извержения последних пяти столетий не оказали существенного влияния на лесные экосистемы высокоширотных и высокогорных районов Сибири по сравнению с вулканическими извержениями первого тысячелетия (540, 1257 гг. н.э.). После ХІІІ в. снижение температуры после мощных стратосферных вулканических извержений не фиксировалось одновременно всеми исследованными параметрами годичных колец и в большинстве случаев отдельные параметры реагировали на эти события спустя год или два. Выявлено, что не все стратосферные вулканические извержения приводят к интенсивному похолоданию и уменьшению осадков в субарктических районах Сибири, экосистемы которых наиболее чувствительны к изменениям климата как на региональном, так и в глобальном масштабах.

\section{Благодарности / Acknowledgements}

Работа выполнена при поддержке РФФИ 16-55-76012 Эра_а («Влияние крупных извержений вулканов на климат и общество Евразии: свидетельства прошлого и прогнозирование будущего», анализ вулканических извержений по данным ширины годичных колец деревьев для субарктики Евразии), EraNet Rus Plus SNF IZRPZ0_16473 («Effects of Large Volcanic eruptions on Eurasian Climate and Societies: unravelling past evidence to predict future impacts», анализ вулканических извержений по данным стабильных изотопов углерода и кислорода в целлюлозе годичных колец деревьев для субарктики Евразии), РНФ 19-14-00028 («Экстремальные (катастрофические) засухи на юге Сибири за последнее тысячелетие», выполнение 
анализа стабильных изотопов углерода и кислорода, измерение анатомических параметров для экстремальных лет, характеризующихся засушливыми условиями в Алтае-Саянском регионе), программы Мария Кюри EU_ISOTREC 235122, 909122 («Climatic and environmental changes in the Eurasian Subarctic inferred from tree-ring and stable isotope chronologies for the past and recent periods», измерение ширины годичных колец и изотопной композиции углерода и кислорода в целлюлозе годичных колец деревьев для субарктических районов Евразии), а также проекта РФФИ 18-45-240001-р_а («Прогноз регионально-специфичных откликов бореальных лесов горных районов Сибири на глобальные изменения природной среды и траекторий эволюции ландшафтов для снижения экологических рисков и эффективного долгосрочного планирования деятельности различных отраслей экономики», анализ и оценка изменения климата в субарктических районах Сибири после аномальных событий глобального масштаба).

Авторы признательны рецензентам данной статьи за рекомендации и ценные советы.

This work was supported by the RFBI 16-55-76012 Era_a granted to E.A. Vaganov to perform analysis of volcanic eruptions based on tree/ring width from Eurasian subarctic and EraNet Rus Plus SNF IZRPZ0_16473, granted to M. Stoffel ("Effects of Large Volcanic eruptions on Eurasian Climate and Societies: unravelling past evidence to predict future impacts", to perform analysis of volcanic eruptions based on stable carbon and oxygen isotopes in tree-ring cellulose for Eurasian Subarctic), Russian Science Foundation RSF 19-14-00028 granted to V.S. Myglan ("Extreme (catastrophic) droughts in the south of Siberia over the past thousand years" for performing stable carbon and oxygen isotope analyses, measurements of wood anatomical parameters for extreme years, characterized by dry conditions in the Altai-Sayan Mountain region); Marie-Curie Individual Fellowship granted to O.V. Churakova (Sidorova) within EU_ISOTREC 235122, 909122 ("Climatic and environmental changes in the Eurasian Subarctic inferred from tree-ring and stable isotope chronologies for the past and recent periods" for revealing climatic and environmental changes after major volcanic eruptions in Eurasian Subarctic); and RFBR 18-45-240001-p_a ("Prognosis of region-specific responses of Siberian mountain forests to global environmental changes and of the landscape development trajectories for mitigation of environmental risks and an effective long-term planning in various economic sectors", for analysis and estimation of climate in Siberian subarctic regions after global anomaly events).

The authors are grateful to anonymous reviewers for comments and valuable suggestions.

\section{Список литературы / References}

Абаимов А.П., Бондарев А.И., Зырянова О.А., Шитова С.А. (1997) Леса Красноярского Заполярья. Новосибирск, Наука, 207 с. [Abaimov A.P., Bondarev A.I., Yzrzanova O.V., Shitova S.A. (1997) Polar forests of Krasnoyarsk region. Novosibirsk, Nauka, 207 p. (in Russian)]

Сидорова О.В., Наурзбаев М.М. (2002) Реакция на климатические изменения лиственницы Каяндера на верхней границе леса и в долине реки Индигирки. Лесоведение, 2: 73-75 [Sidorova O.V., Naurzbaev M.M. (2002) Response of Larix cajanderi to climatic changes at the upper timberline and in the Indigirka River valley. Russian Journal of Forest Science [Lesovedenie], 2: 73-75 (in Russian)]

Baillie M.G.L. (1994) Dendrochronology raises questions about the nature of the AD 536 dust-veil event. Holocene, 4(2): 212-217 
Barinov V.V., Myglan V.S., Taynik A.V., Ojdupaa O.Ch., Agatova A.R., Churakova (Sidorova) O.V. (2018) Extreme climatic events in Altai-Sayan region as indicator of major volcanic eruptions. Geophysical Processes and Biosphere, 17: 45-61

Battipaglia G., Cherubini P., Saurer M., Siegwolf R.T.W., Strumia S., Cotrufo M.F. (2007) Volcanic explosive eruptions of the Vesuvio decrease tree-ring growth but not photosynthetic rates in the surrounding forests. Global Change Biology, 13(6): 1122-1137

Boike J., Kattenstroth B., Abramova K., Bornemann N., Chetverova A., Fedorova I., Fröb K., Grigoriev M., Grüber M., Kutzbach L., Langer M., Minke M., Muster S., Piel K., Pfeiffer E.-M., Stoof G., Westermann S., Wischnewski K., Wille C., Hubberten H.-W. (2013) Baseline characteristics of climate, permafrost and land cover from a new permafrost observatory in the Lena River Delta, Siberia (1998-2011). Biogeosciences, 10(3): 2105-2128

Briffa K.R., Jones P.D., Schweingruber F.H., Osborn T.J. (1998) Influence of volcanic eruptions on Northern Hemisphere summer temperature over the past 600 years. Nature, 393(6684): 450-455

Brönnimann S., Krämer D. (2016) Tambora and the "Year Without a Summer» of 1816. A perspective on earth and human systems science. Geographica Bernensia G90, 48 p.

Büntgen U., Myglan V.S., Ljungqvist F.C., McCormick M., Di Cosmo N., Sigl M., Jungclaus J., Wagner S., Krusic P.J., Esper J., Kaplan J.O., de Vaan M.A.C., Luterbacher J., Wacker L., Tegel W., Kirdyanov A.V. (2016) Cooling and societal change during the Late Antique Little Ice Age from 536 to around 660 AD. Nature Geoscience, 9(3): 231-236

Churakova (Sidorova) O.V., Fonti M.V., Saurer M., Guillet S., Corona C., Fonti P., Myglan V.S., Kirdyanov A.V., Naumova O.V., Ovchinnikov D.V., Shashkin A.V., Panyushkina I.P., Büntgen U., Hughes M.K., Vaganov E.A., Siegwolf R.T.W., Stoffel M. (2019) Siberian tree-ring and stable isotope proxies as indicators of temperature and moisture changes after major stratospheric volcanic eruptions Climate of the Past, 15(2): 685-700

Churakova (Sidorova) O.V., Bryukhanova M.V., Saurer M., Boettger T., Naurzbaev M.M., Myglan V.S., Vaganov E.A., Hughes M.K., Siegwolf R.T.W. (2014) A cluster of stratospheric volcanic eruptions in the AD 530s recorded in Siberian tree rings. Global and Planetary Change, 122: $140-150$

Churakova (Sidorova) O.V., Shashkin A.V., Siegwolf R.T.W., Spahni R., Launois T., Saurer M., Bryukhanova M.V., Benkova A.V., Kuptsova A.V., Peylin P., Vaganov E.A., Masson-Delmotte V., Roden J. (2016) Application of eco-physiological models to the climatic interpretation of $\delta^{13} \mathrm{C}$ and $\delta^{18} \mathrm{O}$ measured in Siberian larch tree-rings. Dendrochronologa, 39: 51-59

D’Arrigo R., Jacoby G., Frank D., Pederson N., Cook E., Buckley B., Nachin B., Mijiddorj R., Dugarjav C. (2001) 1738-years of Mongolian temperature variability inferred from a tree-ring width chronology of Siberian pine. Geophisycal Research Letters, 28(3): 543-546

Fonti P., Bryukhanova M.V., Myglan V.S., Kirdyanov A.V., Naumova O.V., Vaganov E.A. (2013) Temperature-induced responses of xylem structure of Larix sibirica (Pinaceae) from Russian Altay. American Journal of Botany, 100(7): 1332-1343

Fritts H.C. (1976) Tree-rings and climate. Academic Press, 582 p.

Gao C., Robock A., Ammann C. (2008) Volcanic forcing of climate over the past 1500 years: An improved ice core-based index for climate models. Journal of Geophysical Research-Atmospheres, 113(D23): D23111 
Gennaretti F., Huard D., Naulier M., Savard M., Bégin C., Arseneault D., Guiot J. (2017) Bayesian multiproxy temperature reconstruction with black spruce ring widths and stable isotopes from the northern Quebec taiga. Climate Dynamics, 49(11-12): 4107-4119

Gillett N.P., Weaver A.J., Zwiers F.W., Wehner M.F. (2004) Detection of volcanic influence on global precipitation. Geophysical Research Letters, 31(12): L12217

Groisman P.Y.(1992) Possible regional climate consequences of the Pinatubo eruption. Geophysical Research Letters, 19(15): 1603-1606

Guillet S., Corona C., Stoffel M., Khodri M., Lavigne F., Ortega P., Eckert N., Sielenou P.D., Daux V., Churakova (Sidorova) O.V., Davi N., Edouard J.L., Zhang Y., Luckman B.H., Myglan V.S., Guiot J., Beniston M., Masson-Delmotte V., Oppenheimer C. (2017) Climate response to the Samalas volcanic eruption in 1257 revealed by proxy records. Nature Geoscience, 10(2): 123-128

Hughes M.K., Vaganov E.A., Shiyatov S.G., Touchan R., Funkhouser G. (1999) Twentieth-century summer warmth in northern Yakutia in a 600-year context. Holocene, 9(5): 629-634

Iles C.E., Hegerl G.C. (2014) The global precipitation response to volcanic eruptions in the CMIP5 models. Environmental Research Letters, 9(10): 104012

Kelly P.M., Jones P.D., Pengqun J. (1996) The spatial response of the climate system to explosive volcanic eruptions. International Journal of Climatology, 16(5): 537-550

Krakauer N.Y., Randerson J.T. (2003) Do volcanic eruptions enhance or diminish net primary production? Evidence from tree rings. Global Biogeochemical Cycles, 17(4): 1118

LaMarche V.C., Hirschboeck K.K. (1984) Frost rings in trees as records of major volcanic eruptions. Nature, 307(5947): 121-126

Larsen L.B., Vinther B.M., Briffa K.R., Melvin T.M., Clausen H.B., Jones P.D., SiggaardAndersen M.-L., Hammer C.U., Eronen M., Grudd H., Gunnarson B.E., Hantemirov R.M., Naurzbaev M.M., Nicolussi K. (2008) New ice core evidence for a volcanic cause of the A.D. 536 dust veil. Geophysical Research Letters, 35(4): L04708

Lavigne F., Degeai J.-P., Komorowski J.-C, Guillet S., Robert V., Lahitte P., Oppenheimer C., Stoffel M., Vidal C.M., Surono, Pratomo I., Wassmer P., Hajdas I., Hadmoko D.S., Belizal E. (2013) Source of the great A.D. 1257 mystery eruption unveiled, Samalas volcano, Rinjani Volcanic Complex, Indonesia. Proceedings of the National Academy of Sciences of the United States of America, 110(42): 16742-16747

Loader N.J., Robertson I., Barker A.C., Switsur V.R., Waterhouse J.S. (1997) Improved technique for the batch processing of small wholewood samples to alpha-cellulose. Chemical Geology, 136(3-4): 313-317

Lough J.M., Fritts H.C. (1987) An assessment of the possible effects of volcanic eruptions on North American climate using tree-ring data, 1602 to 1900 A.D. Climate Change, 10(3): 219-239

Myglan V.S., Oidupaa O.C., Kirdyanov A.V., Vaganov E.A. (2008) 1929-year tree-ring chronology for the Altai-Sayan region (Western Tuva). Archaeology, Ethnology \& Anthropology of Eurasia, 36(4): $25-31$

Naurzbaev M.M., Vaganov E.A., Sidorova O.V., Schweingruber F.H. (2002) Summer temperatures in eastern Taimyr inferred from a 2427-year late-Holocene tree-ring chronology and earlier floating series. Holocene, 12(6): 727-736 
Omurova G.T., Barinov V.V., Kardash O.V., Vaganov E.A., Myglan V.S. (2018) Reconstruction of extreme paleoclimatic events in northwestern Siberia using ancient wood from Fort Nadym. Archaeology, Ethnology \& Anthropology of Eurasia, 3: 32-40

Panofsky H.A., Brier G.W. (1958) Some applications of statistics to meteorology. University Park, PA. Mineral industries extension services, college of mineral industries, Pennsylvania State University, $224 \mathrm{p}$.

Panyushkina I.P., Hughes M.K., Vaganov E.A., Munro M.A.R. (2003) Summer temperature in northeastern Siberia since 1642 reconstructed from tracheid dimensions and cell numbers of Larix cajanderi. Canadian Journal of Forest Research, 33(10): 1905-1914

Pearson C.L., Dale D.S., Brewer P.W., Kuniholm P.I., Lipton J., Manning S.W. (2009) Dendrochemical analysis of a tree-ring growth anomaly associated with the Late Bronze Age eruption of Thera. Journal of Archaeological Science, 36(6): 1206-1214

Plummer C.T., Curran M.A.J., van Ommen T.D., Rasmussen S.O., Moy A.D., Vance T.R., Clausen H.B., Vinther B.M., Mayewski P.A. (2012) An independently dated 2000-yr volcanic record from Law Dome, East Antarctica, including a new perspective on the dating of the 1450s CE eruption of Kuwae, Vanuatu. Climate of the Past, 8(6): 1929-1940

$R$ Core Team. $R$ (2016) A Language and Environment for Statistical Computing. Vienna, Austria

Rigby E., Symonds M., Ward-Thompson D. (2004) A comet impact in AD 536? Astronomy \& Geophysics, 45(1): 1.23-1.26

Robock A. (2000) Volcanic eruptions and climate. Reviews of Geophysics, 38(2): 191-219

Robock A., Liu Y. (1994) The volcanic signal in Goddard Institute for Space Studies threedimensional model simulations. Journal of Climate, 7(1): 44-55

Robock A., Mao J. (1992) Winter warming from large volcanic eruptions. Geophysical Research Letters, 19(24): 2405-2408

Salzer M.W., Hughes M.K. (2007) Bristlecone pine tree rings and volcanic eruptions over the last 5000 yr. Quaternary Research, 67(1): 57-68

Saurer M., Kirdyanov A.V., Prokushkin A.S., Rinne K.T., Siegwolf R.T.W. (2016) The impact of an inverse climate-isotope relationship in soil water on the oxygen-isotope composition of Larix gmelinii in Siberia. New Phytologist, 209(3): 955-964

Schneider L., Smerdon J.E., Büntgen U., Wilson R.J.S., Myglan V.S., Kirdyanov A.V., Esper J. (2015) Revising mid-latitude summer temperatures back to A.D. 600 based on a wood density network. Geophysical Research Letters, 42(11): 4556-4562

Schweingruber F.H. (1996) Tree rings and environment dendroecology. Paul Haupt Publ Bern, Stuttgart, Vienna, $609 \mathrm{p}$.

Sidorova O.V., Naurzbaev M.M., Vaganov E.A. (2005) Response of tree-ring chronologies growing on the Northern Eurasia to powerful volcanic eruptions. Problems of Ecological Monitoring and Ecosystem Modeling, 20: 60-72 (in Russian)

Sidorova O.V., Saurer M., Myglan V.S., Eichler A., Schwikowski M., Kirdyanov A.V., Bryukhanova M.V., Gerasimova O.V., Kalugin I.A., Daryin A.V., Siegwolf R.T.W. (2012) A multiproxy approach for revealing recent climatic changes in the Russian Altai. Climate Dynamics, 38 (1-2): $175-188$ 
Sidorova O.V., Siegwolf R.T.W., Myglan V.S., Ovchinnikov D.V., Shishov V.V., Helle G., Loader N.J., Saurer M. (2013) The application of tree-rings and stable isotopes for reconstructions of climate conditions in the Russian Altai. Climatic Change, 120(1-2): 153-167

Sidorova O.V., Siegwolf R.T.W., Saurer M., Naurzbaev M.M., Shashkin A.V., Vaganov E.A. (2010) Spatial patterns of climatic changes in the Eurasian north reflected in Siberian larch tree-ring parameters and stable isotopes. Global Change Biology, 16(3): 1003-1018

Sidorova O.V., Siegwolf R.T.W., Saurer M., Naurzbaev M.M., Vaganov E.A. (2008) Isotopic composition $\left(\delta^{13} \mathrm{C}, \delta^{18} \mathrm{O}\right)$ in wood and cellulose of Siberian larch trees for early Medieval and recent periods. Journal of Geophysical Research-Biogeosciences, 113(G2): G02019

Sigl M., McConnell J.R., Layman L., Maselli O., McGwire K., Pasteris D., Dahl-Jensen D., Steffensen J.P., Vinther B., Edwards R., Mulvaney R., Kipfstuhl S. (2013) A new bipolar ice core record of volcanism from WAIS Divide and NEEM and implications for climate forcing of the last 2000 years. Journal of Geophysical Research-Atmospheres, 118(3): 1151-1169

Sigl M., Winstrup M., McConnell J.R., Welten K.C., Plunkett G., Ludlow F., Buentgen U., Caffee M., Chellman N., Dahl-Jensen D., Fischer H., Kipfstuhl S., Kostick C., Maselli O.J., Mekhaldi F., Mulvaney R., Muscheler R., Pasteris D.R., Pilcher J.R., Salzer M., Schuepbach S., Steffensen J.P., Vinther B.M., Woodruff T.E. (2015) Timing and climate forcing of volcanic eruptions for the past 2,500 years. Nature, 523(7562): 543-549

Stoffel M., Khodri M., Corona C., Guillet S., Poulain V., Bekki S., Guiot J., Luckman B.H., Oppenheimer C., Lebas N., Beniston M., Masson-Delmotte V. (2015) Estimates of volcanic-induced cooling in the Northern Hemisphere over the past 1,500 years. Nature Geoscience, 8(10): 784-788

Stothers R.B. (1984a) Mystery cloud of AD 536. Nature, 307(5949): 344-345

Stothers R.B. (1984b) The great Tambora eruption in 1815 and its aftermath. Science, 224(4654): 1191-1198

Stothers R.B. (1999) Volcanic dry fogs, climate cooling and Plague pandemics in Europe and the Middle East. Climatic Change, 42(4): 713-723

Stothers R.B. (2000) Climatic and demographic consequences of the massive volcanic eruption of 1258. Climatic Change, 45(2): 361-374

Sugimoto A., Yanagisawa N., Naito D., Fujita N., Maximov T.C. (2002) Importance of permafrost as a source of water for plants in east Siberian taiga. Ecological Research, 17(4): 493-503

Toohey M., Sigl M. (2017) Volcanic stratospheric sulphur injections and aerosol optical depth from 500 BCE to 1900 CE. Earth System Science Data, 9(2): 809-831

Vaganov E.A., Hughes M.K., Shashkin A.V. (2006) Growth dynamics of conifer tree rings. Springer Verlag, Berlin, 353 p.

Zielinski G.A., Mayewski P.A., Meeker L.D., Whitlow S., Twickler M.S., Morrison M., Meese D.A., Gow A.J., Alley R.B. (1994) Record of volcanism since 7000 BC from the GISP2 Greenland ice core implications for the volcano-climate system. Science, 264 (5161): 948-952

Wegmann M., Brönnimann S., Bhend J., Franke J., Folini D., Wild M., Luterbacher J. (2014) Volcanic influence on European summer precipitation through monsoons: Possible cause for "years without summer". Journal of Climate, 27(10): 3683-3691 